\title{
Meta-análisis: la ducha vaginal aumenta el riesgo de enfermedad pélvica inflamatoria, de embarazo ectópico y de cáncer de cuello
}

Vaginal douching and adverse health effects: a meta-analysis. Zhang J, Thomas E, Leybovich E. Am J Public Health 1997;87:1201-11

\section{Objetivo}

Evaluar la asociación de las duchas vaginales con la enfermedad pélvica inflamatoria (EPI), el embarazo ectópico o el cáncer de cuello.

\section{Fuente de Datos}

Búsqueda en MEDLINE de estudios en idioma inglés (1965-1995).

\section{Selección de Estudios}

Se incluyeron estudios que reportaran datos de la asociación de la práctica de duchas vaginales regularmente con la incidencia de EPI, embarazo ectópico o cáncer de cervix. Todos los estudios hallados fueron de tipo caso-control.

\section{Extracción de los datos}

Riesgo relativo +/- IC 95\% combinado de los estudios ajustados por distintos factores confundidores.

\section{Resultados Principales}

El 37\% de las mujeres en edad reproductiva (15-44 años) utilizan la ducha vaginal regularmente, y la mitad de éstas por lo menos 1 vez a la semana. Hubo asociación entre la ducha vaginal y el menor estado socioeconómico. La práctica de DV era más frecuente en mujeres de raza negra comparada con las blancas (2/3 vs. $1 / 3)$. La incidencia acumulativa de EPI es de $10 \%$ hasta los 45 años. Las mujeres que utilizan la DV tienen un aumento de riesgo del 73\% (OR 1.73, IC95\% 1.07-2.79), las que se duchan $\geq 1 /$ semana tienen un riesgo casi cuatro veces mayor (0R 3.9, IC95\% 3.2-4.6). La asociación con embarazo ectópico también fue importante en las mujeres que se duchan (OR 1.76, IC95\% 1.10-2.82) y el riesgo aumenta más en las que utilizan preparados comerciales. En cuanto al cáncer de cuello, las que se duchan alguna vez no tienen mayor riesgo (OR 1.25, IC 95\% 0.991.59) pero el riesgo aumenta en las mujeres que se duchan $\geq 1 / \mathrm{sem}-$ ana (OR 1.86, IC95\% 1.29-2.68).

\section{Conclusión}

La ducha vaginal aumenta el riesgo de EPI, de embarazo ectópico y también de cáncer de cuello (éste último sólo aumenta en las que se duchan $\geq 1 /$ semana). La asociación entre cáncer cervical y lavado vaginal debe investigarse un poco más ya que no es tan clara como las antes mencionadas.

\section{COMENTARIO}

Existen múltiples trabajos publicados que muestran la asociación entre lavado vaginal y enfermedad inflamatoria pelviana (1), embarazo ectópico (2) y disminución de la fertilidad (3). El riesgo está en relación directa con la frecuencia de uso del procedimiento a partir de dos Lavados vaginales por año. Es difícil dudar acerca de que ésta es una práctica posible de reducir a través de la acción médica. Sin embargo, no suele ser un dato que se indague en el interrogatorio de mujeres durante consultas no ginecológicas, y aún dentro de ellas si no se trata de un caso de EPI.

En cuanto a la calidad metodológica del presente meta-análisis, el restringir la búsqueda sólo a artículos en inglés limita la validez externa y aumenta el sesgo de selección (si había algún artículo en otro idioma no se lo buscaba y por lo tanto, no se analizaba). Los factores confundidores se tuvieron en cuenta correctamente, especialmiente la clase social, que también es un factor de riesgo para EPI, embarazo ectópico y cáncer de cuello. Este comentario es todavía más relevante si se tiene en cuenta que el uso del lavado vaginal se observó más en mujeres de clase social baja que, a su vez, tienen mayor riesgo. El momento del ciclo menstrual en el que se realice la DV puede tener importancia. En la mitad del ciclo el moco cervical es más fluído y más fácil de barrer, y el orificio interno del cuello está entreabierto. Esto implica que de realizarse la DV, esta debe ser infrecuente y lejos de la ovulación (4-5). De todos modos es claro que un método que no tiene beneficios reportados y que posiblemente se asocie a efectos adversos en la salud femenina es completamente innecesario dentro de la rutina de higiene de la mujer. Este estudio es un punto de partida para mejorar la salud de la población no sólo a través de las grandes campañas sino también por la acción mancomunada en el consultorio de cada médico.

\section{Referencias}

1)Sholes D, Dailing JR, Stergaschis A. Vaginal douching as a risk factor for acute pelvic inflammatory disease. Obstet Gynecol 1993; 81(4): 601-606

2) Kendrick JS, Atrash HK, Strauss LT. Vaginal douching and the risk of ectopic pregnancy among black women.

Am J Obstet Gynecol 1997: 176(5): 991-997

3) Baird DD, Weinberg CR, Voigt LF. Vaginal douching and reduced fertility. Am J Public Health 1996; 86(6): 844-850

4) Onderdonk AB, Delaney ML, Hinkson PL. Quantitative and qualitative effects of douche preparations on vaginal microflora. Obstet Gynecol 1992; 80 (3 Pt 1): 333-338 5) Rosenberg MJ, Philips RS. Does douching promote ascending infection. J Reprod Med 1992; 37(11): 930-938. 